\title{
Cadastro Territorial como instrumento de desenvolvimento de projetos de requalificação urbana
}

\author{
Ricardo J. Bonilla* \\ Andrea F.T. Carneiro ${ }^{* *}$
}

Recebido el 21 de abril de 2015; aceito el 16 de agosto de 2015

\section{Resumen}

La importancia de las informaciones territoriales integradas generadas por el Catastro Multifinalitario para acciones de planeamiento urbano, motivó la realización de esta investigación, cuyo objetivo principal es analizar el contenido y la aplicación del Catastro Multifinalitario como instrumento para la recalificación urbana. A través de un experimento realizado con el apoyo de geotecnologías, se buscó identificar y seleccionar inmuebles que atiendan a parámetros predefinidos para sugerir su recalificación. La zona elegida para el análisis propuesto fue la colonia Boa Vista y alrededores, ubicada en la zona central de la ciudad de Recife$\mathrm{PE}$, Brasil, que posee una gran variedad de inmuebles y servicios, una ocupación caracterizada por zonas en franca expansión inmobiliaria que contrasta con zonas de abandono y deterioro urbano. Como resultados, se presentan en este artículo la metodología y las conclusiones de los análisis efectuados para la identificación de terrenos con la finalidad de ocupación por reemplazo y terrenos cuyo potencial constructivo pueda ser trasferido a otro inmueble.

Palabras clave: catastro multifinalitario, recalificación urbana, planeamiento urbano.

\footnotetext{
Abstract

The importance of the integrated territorial information generated by the multipurpose cadastre for urban planning actions motivated the realization of this

* Alumno del Programa de Maestría y Doctoramiento en Desarrollo Urbano de la Universidade Federal de Pernambuco, Brasil (UFPE), e-mail: ricardobonilla@gmail.com

** Profesora del Departamento de Ingeniería Cartográfica de la Universidade Federal de Pernambuco, Brasil (UFPE), e-mail: aftc@ufpe.br
} 
research, whose principal objective is to analyze the content and the application of the multipurpose cadastre as an instrument for urban requalification. Through the analysis, carried out with the aid of geotechnologies based on Geographic Information Systems, the aim was to identify and select properties that attend predefined parameters, with the purpose of suggesting their requalification. The area chosen for the proposed analysis was the Boa Vista district and adjacent areas. Localized in the central region of Recife city, Brazil, which have a great variety of properties and services, whose occupation is characterized by areas that are in real state expansion, in contrast with abandoned zones and urban deterioration. As a result. As a result, we present in this article the methodology and results of analyzes for the identification of land for the position for replacement and land whose constructive potential can be transferred to another property.

Key words: multipurposecadastre, urbanrequalification, urbanplanning.

\section{Resumo}

A importância das informações territoriais integradas geradas pelo Cadastro Multifinalitário para ações de planejamento urbano motivou a realização desta pesquisa, cujo objetivo principal é analisar o conteúdo e a aplicação do Cadastro Multifinalitário como instrumento para a requalificação urbana. Através de um experimento realizado com o apoio de geotecnologias, procurou-se identificar e selecionar imóveis que atendam a parâmetros predefinidos, a fim de sugerir a sua requalificação. A área escolhida para a análise proposta foi o bairro da Boa Vista e adjacências, localizado na região central da cidade de Recife-PE, Brasil, que possui uma grande variedade de imóveis e serviços, e uma ocupação caracterizada por áreas em franca expansão imobiliária, contrastadas com zonas de abandono e deterioração urbana. Como resultados, apresentam-se neste artigo a metodologia e os resultados das análises realizadas para a identificação de terrenos com o fim de ocupação por substituição e terrenos cujo potencial construtivo possa ser transferido para outro imóvel.

Palavras chaves: cadastro multifinalitário, requalificação urbana, planejamento urbano.

\section{Introdução}

Segundo Erba (2005), o Cadastro Multifinalitário urbano se presta como ferramenta fundamental para o planejamento das cidades, à medida que fornece informação precisa (dados físicos situados em um sistema cartográfico) associada a parâmetros como localização geográfica de todos os imóveis da cidade, ocupação ou finalidade de cada imóvel, uso atual do solo dentro de cada imóvel, entre outros. 
O trabalho desenvolvido procurou estabelecer o papel do cadastro multifinalitário como uma das principais ferramentas para o planejamento urbano. Através do uso dos dados pertencentes a diversos cadastros territoriais de Recife, esta pesquisa buscou identificar imóveis com as seguintes características, importantes para projetos de requalificação urbana:

I. Lotes que permitam o uso comercial para estacionamento;

II. Edificações que permitam a recuperação/reutilização, com a finalidade de uso habitacional;

III. Imóveis para a ocupação por complementação, com a finalidade de uso habitacional;

IV. Terrenos para a ocupação por substituição, sem finalidade pré-determinada;

V. Terrenos cujo Potencial Construtivo possa ser transferido para outro imóvel baseado no instrumento da TDC - Transferência do Direito de Construção, descrito no Estatuto das Cidades (Brasil, 2005).

Neste artigo, baseado em Bonilla (2007), são apresentados os resultados das análises realizadas para atender aos itens 'IV' $\mathrm{e}$ ' $\mathrm{V}$ '.

\section{O Cadastro Territorial Multifinalitário (CTM)}

Já nos primórdios da civilização, surge a necessidade de identificar a porção territorial possuída por cada cidadão, seja para fins de tributação, seja para garantia da posse ou propriedade. Independentemente do modelo cadastral atualmente desenvolvido em cada país, pode-se identificar uma função comum: todos os cadastros visam a identificar unidades territoriais (que podem ser imóveis ou parcelas) e seus ocupantes (ou proprietários). Por outro lado, a concentração das populações em áreas urbanas vem aumentar a complexidade das relações do homem com a terra, de tal forma que, a eficiência da gestão territorial urbana passa a depender das informações territoriais integradas que podem ser proporcionadas por um cadastro multifinalitário moderno.

Sistemas cadastrais eficientes apoiam mercados imobiliários efetivos, aumentam a produtividade da agricultura, facilitam o desenvolvimento sustentável, o gerenciamento ambiental, a estabilidade política e a justiça social (Williamson, Apud Carneiro, 2003).

Um CTM caracteriza-se como uma base oficial de dados físicos/geométricos, jurídicos e econômicos, metodicamente organizados, referentes a unidades territoriais. A multifinalidade pressupõe a utilização dessa base única por diferentes usuários e, segundo Águila e Erba (2006), esta multifinalidade se consegue 
mediante a 'coordenação' e não a partir da 'centralização' de dados e informações. Alcázar (2007) lembra que a ordenação territorial é a ferramenta fundamental para estabelecer as grandes linhas de desenvolvimentos futuros, os critérios para regular a evolução das cidades e seu entorno, os investimentos em infraestrutura e espaços produtivos e muitas outras utilizações que se poderiam citar.

Para que o CTM possa cumprir a sua finalidade original, devem ser considerados aspectos administrativos, que promovam a integração entre instituições e o compartilhamento das informações, legais, que proporcionem um marco jurídico para ações cadastrais e técnicas atribuindo responsabilidades e direitos sobre a sua implementação e gerenciamento, e técnicas, para um melhor uso das geotecnologias disponíveis bem como a identificação única de imóveis e uma perfeita compilação de levantamentos e plantas produzidos pelos diferentes provedores da informação.

\section{O CTM no Planejamento Urbano}

É impossível administrar uma propriedade sem conhecê-la em sua essência, pois seu valor advém de sua exploração segundo a sua aptidão (Dresbach, Apud Erba, 2005).

O cadastro técnico multifinalitário urbano fornece informação precisa associada a parâmetros como:

- Ocupação ou finalidade de cada imóvel;

- Uso atual do solo dentro de cada imóvel;

- Áreas de litígio entre imóveis confrontantes;

- Regularização de títulos segundo as áreas;

- Base para a implementação de infraestrutura;

- Avaliação do imóvel para desapropriação, visando obras públicas;

- Base para o gerenciamento da construção civil, entre outros.

Para Erba (2005), os cadastros temáticos mais importantes inseridos no ambiente urbano são:

- Cadastro da rede viária urbana

- Cadastro da rede de drenagem natural (córregos, riachos e rios): permite uma série de correlações lineares com o saneamento básico, a saúde e a educação

- Cadastro imobiliário: correlaciona a parcela e o imóvel construído às leis vigentes que atuam nesta;

- Cadastro planialtimétrico urbano: fundamental para o planejamento dos serviços de infraestrutura urbana; 
- Cadastro tributário: base para o lançamento de tributos, impostos e taxas de serviços. Sua atualização é fundamental;

- Cadastro de áreas verdes e de lazer;

- Cadastro de serviços de infraestrutura;

- Cadastro de glebas: provê de dados a planta de valores genéricos (base do sistema tributário urbano da cidade).

Mais do que o desafio contínuo de gerar informação territorial confiável e atualizada para a formação do CTM, constata-se a necessidade de padronizar processos e produtos relacionados à informação territorial no Brasil, a fim de que se possa disponibilizar o seu uso por parte das instituições públicas e privadas, dos profissionais interessados e da população em geral.

\section{As Geotecnologias e o CTM}

O uso de Sistemas de Informação Geográfica (SIG) em aplicações urbanas é destacado por Piumeto (2006), como uma ferramenta que permite analisar, documentar, modelar, desenhar, implementar e gerir todas as situações do território que requerem uma adequada intervenção do estado local, desde seu estudo até a definição das políticas:

- Permitem modelar o espaço geográfico (ou território) integrando os dados cartográficos com fotos aéreas, imagens de satélites e bases de dados alfanuméricas, possibilitando a construção e manutenção de "modelos" precisos para o estudo, análise e a tomada de decisões sobre o território;

- Integram dados de distintas fontes, estruturas e formatos, armazenam informação descritiva (atributos) dos dados geográficos, bem como seus metadados, são capazes de trabalhar com distintos níveis de detalhe da informação geográfica segundo a escala de análise (generalização cartográfica) e possuem funções profissionais para a produção cartográfica;

- Realizam análise espacial, a partir do modelo construído do espaço geográfico permitem o desenvolvimento de análise de redes, análise sobre o relevo, superposição de dados, avaliação multicritério para a escolha de locais específicos, interpolação e obtenção de modelos, cálculo de geoestatísticas, etc;

- São capazes de apoiar análises multitemporais de dados geográficos, analisando processos de câmbio, degradação de zonas naturais, crescimento urbano, etc;

- Possibilitam e facilitam o trabalho multidisciplinar, disponibilizando acessos multiusuários organizados segundo o tipo de usuário (manutenção de dados, análise ou simples consultas) e proporcionando a cada um as ferramentas específicas para o trabalho em equipe. 
Graafland (1999) define um sistema para a infraestrutura de geoinformação (GIinfrasctructure ou em português SIG corporativo), trata-se de uma organização estruturada e uma rede integrada de conhecimentos e ferramentas técnicas para uso comum e múltiplo na organização como um todo. Destaca como elementos importantes desta infraestrutura: uma política de informação estratégica e tomada de decisão; redes computacionais e data warehouse.

Outra tendência de sistemas cadastrais modernos é a disponibilização de seus dados via internet, o e-cadastro, o que permite a democratização da informação cadastral promovendo uma maior transparência no processo. Os desafios e implantação destes sistemas são discutidos em publicações recentes, como Dang (2007), Hawerk (2006) e Riecken (2007).

\section{Cartografia e Cadastro do Recife}

Em Recife, a SEFIN (Secretaria de Finanças da Prefeitura do Recife) possui o Departamento de Tributos Imobiliários (DTI), o qual é responsável pela tributação imobiliária, ou seja: a manutenção do cadastro imobiliário e a administração e lançamentos do IPTU (Imposto Sobre a Propriedade Predial e Territorial Urbana), do ITBI (Imposto sobre a Transmissão de Bens Imóveis) e os direitos relativos, a Taxa de Limpeza Pública, a Contribuição para Custeio da Iluminação Pública e a Contribuição de Melhorias (Sarubbi Neto, 2005). A partir deste fato pode-se entender a necessidade fundamental de se ter um cadastro consistente e preciso que, além de atualizado, seja capaz de acompanhar a dinâmica do crescimento urbano.

De acordo com Sarubbi Neto (2005), a Prefeitura conta hoje com as seguintes bases de informações oficiais:

- Base Cartográfica Unificada, UNIBASE, resultado de convênio celebrado em 1984 por 14 prefeituras da região metropolitana do Recife, a FIDEM (Fundação Instituto de Desenvolvimento Municipal e Metropolitano), as concessionárias de serviços públicos, órgãos de transito e a EMTU (Empresa Metropolitana de Transporte Urbano), disponível em meio digital e planejada na escala 1/1.000. A UNIBASE encontra-se desatualizada em função da demora ocorrida na sua elaboração, na falta de investimentos para a sua atualização temporal e na falta um de feedback por parte de todos os conveniados (os quais restringiram as atualizações por eles feitas ao uso interno) que proporcionasse uma diversificação das informações contidas;

- Cadastro Imobiliário Fiscal, descritivo e com as inconsistências de informações, localização ou, até mesmo, de inexistência de imóveis cadastrados;

- Mapa Urbano Básico, com informações de quadras e suas faces. Encontra-se desatualizado e possui uma base gráfica que diverge da UNIBASE; 
- Recadastramento Predial 1997-2000. Realizado nesse período, levantou cerca de $50 \%$ dos imóveis cadastrados do Recife;

- Cadastro de Logradouros. Plantas analógicas de referência em escala 1/5.000;

- Plantas de Quadra, disponíveis em meio analógico, encontram-se no Departamento de Tributos Imobiliários da Secretaria de Finanças. Além de desatualizadas, têm o seu acervo incompleto;

- Imagens de satélite de alta resolução. Imageadas no $2^{\circ}$ Semestre de 2000 pelo satélite Quickbird, apresentaram problemas de referenciamento em relação à UNIBASE. A SEPLAM também possui os cadastros de Infraestrutura e os de Regularização do Uso do Solo, com a finalidade de prestar suporte às ações de planejamento, controle e gestão urbana. Estes são compostos da seguinte forma:

- Cadastros de Infraestrutura. Base de endereçamento da Prefeitura tem o registro atual e histórico das denominações, das delimitações (distrito, bairro e Regiões Político Administrativas — RPAs) e é a base de cálculo para o IPTU e de informações para o Planejamento Urbano. Composto por: Cadastro de Logradouros e de Serviços Publicos;

- Cadastros de Regularização de Uso. Controla os processos de licenciamento modificação e uso das parcelas urbanas bem como a aprovação de projetos de edificações.Composto de: Cadastros de Zoneamento, de Plantas Oficiais - loteamentos e projetos viários, Cadastros de Interferência Urbanística, Cadastros de Processos Urbanísticos.

O acervo cartográfico na Prefeitura do Recife foi elaborado a partir de um mosaico de fotos aéreas de épocas diferentes $(1983,1987,1988$ e 1997) que foi restituído e nunca atualizado. Os trabalhos de levantamento, quando realizados, na maioria das vezes são feitos com o uso de trenas e com o método de contorno de quadra, a fim de localizar entidades. O referido acervo é composto por:

- Ortofotocartas em escalas 1:10.000 e 1:2.000;

- Carta de Nucleação na escala 1:25.000;

- Carta de traço na escala 1:1.000 (UNIBASE);

- Carta de traço do Cadastro de Logradouros, nas escalas 1:10.000 e 1:5.000;

- Foto quadras na escala 1:1.000;

- Carta Imagem, do satélite Quickbird;

- Plantas de Projetos Setoriais, em várias escalas;

- Mapas Temáticos em várias escalas;

- Plantas de Regularização do Uso do Solo em várias escalas: Loteamentos, Projetos viários, Desmembramento e remembramento, Desapropriações.

Apesar de se ter mais de uma década do recebimento das Plantas UNIBASE, ainda não se conseguiu institucionalizar o seu uso. 


\section{Metodologia}

O experimento realizado fundamenta-se na coleta dos dados cadastrais, na utilização de um programa de SIG para a parametrização dos dados, e na análise e interpretação dos resultados pelo usuário. Procurou-se o seu desenvolvimento de forma que fosse facilmente reproduzido, modificado e/ou adaptado por um novo usuário a fim de incentivar a sua reprodução.

O marco legal se caracteriza pelas seguintes Leis: O Plano Diretor do Recife, Lei $n^{\circ}$ 15.547/91 que, entre outros, estabelece a TDC (Transferência do Direito de Construção); A Lei de Uso e Ocupação do Solo (LUOS), Lei no 16.176/96 que define os parâmetros urbanísticos reguladores da ocupação do solo urbano (a TSN (Taxa de Solo Natural), o $\mu$ (Coeficiente de Utilização); a Lei de Edificações e Instalações, 16.292/97 que, entre outros, estabelece as dimensões e áreas mínimas dos ambientes e regulamenta o número de vagas. O Decreto Lei $\mathrm{n}^{\circ} 25$, de 30.11.1937 que institui o tombamento em nível federal e que sugere o polígono de preservação do entorno destes imóveis; A Lei Estadual 7.970/79 que institui o tombamento em nível estadual; A Lei 16.284/97 que relaciona e normatiza os Imóveis Especiais de Preservação (IEPs), regulamentando a TDC que os proprietários destes imóveis podem requerer.

\section{Coleta dos dados}

A área escolhida localiza-se na região central do Recife, próxima a centros financeiros, administrativos, comerciais e de serviços da cidade. Apesar do centro da cidade sofrer com o processo de esvaziamento e migração de atividades e serviços para outras regiões, notado nas grandes capitais, a área se caracteriza por ter um pólo médico de caráter nacional em franco desenvolvimento. Outro fato é o interesse do poder municipal e estadual na recuperação da RPA1 com o desenvolvimento de estudos que buscam a requalificação urbana da região como o Projeto do "Complexo Turístico Recife - Olinda". A área escolhida também tem sido objeto de estudos desenvolvidos pela SEPLAM, o que propiciou a disponibilidade de dados utilizados nesta pesquisa.

A escolha da área de estudo foi condicionada à disponibilidade de dados que viabilizassem a análise pretendida. A intenção foi a de escolher uma área que se caracterizasse por possuir zonas subutilizadas, que fosse provida de infraestrutura e serviços urbanos, mas que não fosse centro de atenção da especulação imobiliária. Os dados cadastrais foram obtidos na sede da Prefeitura do Recife, através da SEPLAM, que disponibilizou um levantamento do estoque imobiliário disponível na RPA1, concluído em Setembro de 2006. 


\section{Base cartográfica}

A cartografia foi originada do projeto UNIBASE, que se utilizou das fotografias aéreas tomadas em voos realizados entre 1997 e 1998, na escala 1:6.000, para proceder à sua restituição analítica. As cartas utilizam a projeção UTM (Projeção Transversa de Mercator), no sistema geodésico de referência SAD-69 (South American Datum) com o vértice planimétrico em Chuá (Arruda, 2003).

\section{Levantamento do estoque imobiliário da RPAI}

Foram utilizados dados de trabalho realizado para a SEPLAM, que levantou em campo informações relativas ao uso do imóvel, estado de conservação, condições de ocupação e atividade instalada. As informações foram associadas ao Cadastro de Imóveis da Prefeitura - CADIMO, de onde foram obtidas as áreas de construção e do terreno para cada imóvel, a fim de dimensionar e relacionar o estoque imobiliário existente com os parâmetros pesquisados. Desse cadastro também foi adotada a chave de identificação de cada imóvel, denominada DSQFL: Distrito, Setor, Quadra, Frente, Lote.

\section{Caracterização da área de estudo}

A RPA-1 encontra-se na área central do Recife, concentrando as mais importantes funções da região metropolitana: Porto, centros financeiros, centros administrativos, comerciais e de serviços, escolas, faculdades, equipamentos de turismo e lazer, além de ser o principal ponto de convergência do transporte público da cidade. Portanto, é natural que se pense na sua recuperação e na consolidação do seu desenvolvimento. Na RPA1 localiza-se o centro principal da cidade, composto pelos Bairros do Recife, São José, Santo Antônio, Boa Vista, Soledade, Santo Amaro e, segundo Recife (2005), há a predominância de imóveis destinados a atividades comerciais (atacadistas e de varejo) e de serviços.

\section{Tratamento dos dados}

\section{Dados analíticos}

Dados gráficos compostos por: plantas das ZEPHs (Zonas Especiais de Preservação do Patrimônio Histórico Cultural), obtidas na DPPC (Diretoria de Preservação de Patrimônio Construído, da Secretaria de Cultura da Prefeitura do Recife); relação de IEPs obtida no site da Prefeitura do Recife; relação dos imóveis de preservação em nível Estadual, obtida na FUNDARPE (Fundação do Patrimônio Histórico e Artístico de Pernambuco); relação dos imóveis de Preservação em nível Federal, pesquisados em bibliografia e consultas na $5^{\text {a }}$ SR do IPHAN (Instituto do Patrimônio Histórico e Artístico Nacional); e Plantas dos polígonos de preservação existentes na área de estudo obtidos junto ao IPHAN. 


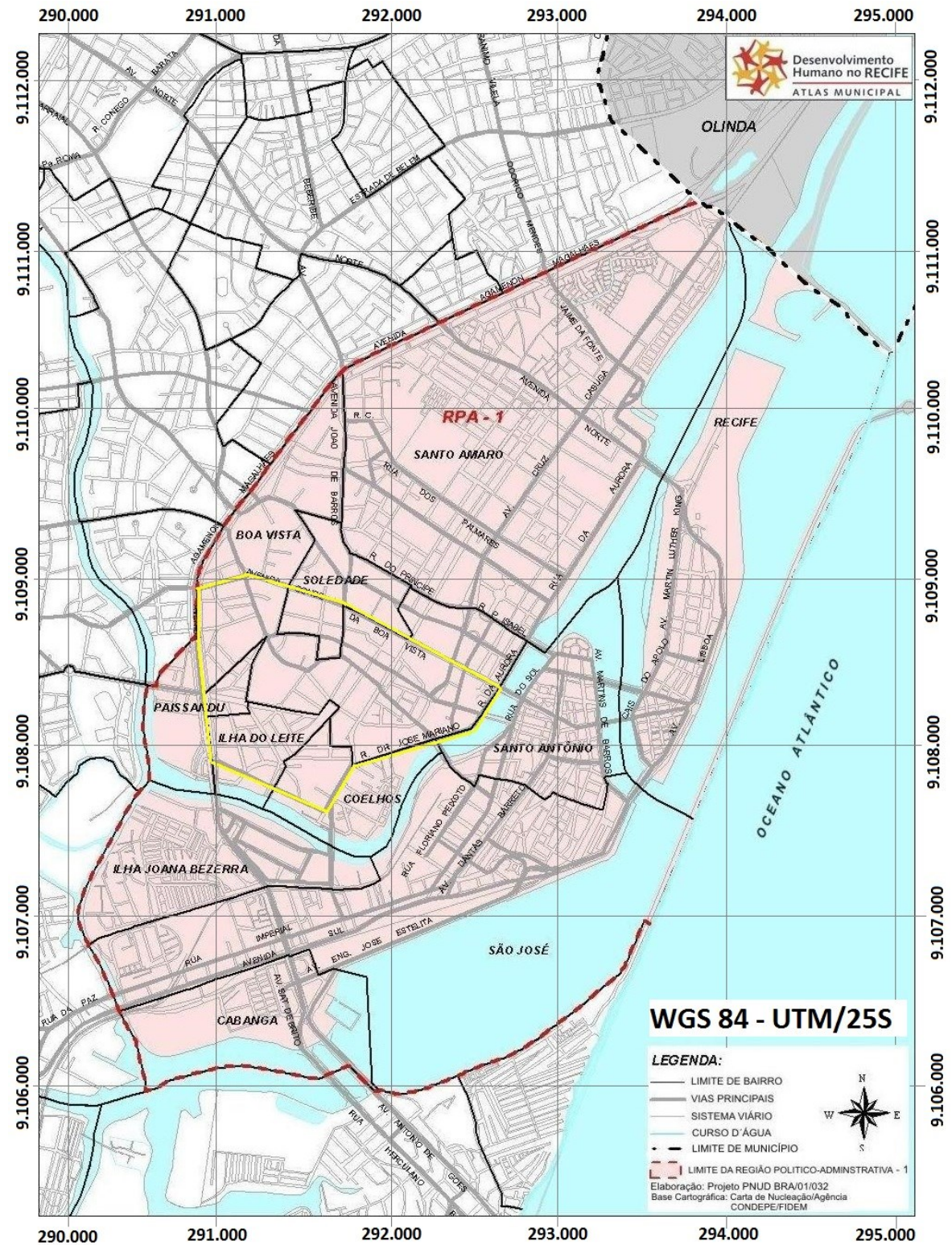

Figura 1. RPA1 com a área de estudo em amarelo.

Fonte: Atlas Municipal do Recife. 


\section{Dados em meio eletrônico}

Dados descritivos do CADIM, da SEFIN e do Levantamento de Imóveis, obtidos na SEPLAM; dados gráficos por arquivos eletrônicos DXF, baseadas nas plantas da UNIBASE; shapes com os temas tratados no levantamento de imóveis da RPA1 (referenciados aos dados tabulares pelo campo "DSQFL"); arquivos digitais das plantas ZEPH-08, ZEPH-18 e ZEPH-20, obtidas na DPPC; arquivos digitais DWF dos polígonos de preservação "Palácio da Soledade / casa de Oliveira Lima" e "Igreja das Fronteiras", contidos na área de estudo, obtidos no IPHAN; arquivos digitais DXF das plantas da UNIBASE, correspondentes à área de estudo, obtidas junto à FIDEM.

\section{Tratamento dos dados descritivos}

As tabelas CADIMO e SEFIN e Dados Gerais, foram comparadas para uma rápida verificação e foi constatado que a tabela CADIMO não continha o campo DSQFL, mas sim um campo individual de cada número da chave (Distrito, Setor, Quadra, Frente e Lote) sendo necessária a criação deste campo para prosseguir na comparação. Para a montagem da tabela de dados a ser utilizada no SIG, foram utilizados os campos das tabelas coletadas, conforme mostrado na Tabela 1.

Tabela 1

Esquema de coleta de dados

\begin{tabular}{lccc}
\hline \multicolumn{1}{c}{ Campo } & CADIMO & SEFIN & Dados Gerais \\
\hline Código DSQFL & & $\mathrm{X}$ & $\mathrm{X}$ \\
Área total de construção & $\mathrm{X}$ & & $\mathrm{X}$ \\
$\mathrm{N}^{\circ}$ de pavimentos & $\mathrm{X}$ & $\mathrm{X}$ & $\mathrm{X}$ \\
Formato do terreno & $\mathrm{X}$ & & \\
Testada fictícia & $\mathrm{X}$ & & \\
Testada principal & $\mathrm{X}$ & & $\mathrm{X}$ \\
Recuos & & $\mathrm{X}$ & $\mathrm{X}$ \\
Condição de ocupação & & $\mathrm{X}$ & \\
Tipologia da edificação & $\mathrm{X}$ & & \\
Estado de conservação & $\mathrm{X}$ & $\mathrm{X}$ & \\
Patrimônio & $\mathrm{X}$ & & \\
Atividade instalada & & $\mathrm{X}$ & \\
\hline
\end{tabular}

Fonte: Elaboração própria. 
Uma vez montada a tabela de dados, procedeu-se à exclusão das chaves repetidas. Como um lote possui subunidades (apartamentos) há uma grande repetição de eventos para uma mesma chave. Após a exclusão, a tabela original que possuía em torno de 10.000 linhas, ficou reduzida a 2.300 linhas com a eliminação das subunidades.

\section{Tratamento dos dados gráficos}

Foram utilizados os shapes da RPA1: Hidrografia Principal, Bairros, Quadras, Lotes. Edificações e Sistema Viário e com a intersecção do shape criado da delimitação da área de estudo, foram produzidos shapes dos temas citados, para a área de estudo. Os shapes coletados continham os polígonos identificados com a chave DSQFL, mas sem atributos. Após a delimitação da área de estudo iniciou-se uma verificação quadra a quadra para:

- Identificar e visualizar os setores componentes da área de estudo: 1550, 1555, 1560 e 1585, passando-se a identificar a numeração das quadras por cada setor;

- Identificar os setores de levantamento 4, 5 e 6 e demarcar a área de estudo;

- Conferir a compatibilidade entre o código dos polígonos registrados no shape e a existência dos mesmos nas tabelas do CADIMO; para tanto, foram escolhidos 04 lotes, de forma aleatória, em cada quadra, e verificados na tabela CADIMO.

Para a realização das análises pretendidas, foram criados os temas Poly_iphan, Poly_spr, Poly_spae Poly_zecp correspondendo aos polígonos de preservação do IPHAN, do Setor de Preservação Rigoroso (SPR), do Setor de Preservação Ambiental (SPA) e à Zona Especial de Centro Primário, respectivamente (ZECP). A partir destes temas, em intersecção com o tema lotes, foram atribuídos os valores 0 - não contido e 1 - contido pelo tema correspondente, nos campos criados: iphan, spr, spae zecp.

A seguir, os shapes de edificações foram complementados com o campo: Área de Construção, correspondendo à área ocupada pela edificação existente e o campo Restrição, com o preenchimento dos valores Livre - IEP - FUNDARPE Monumento, correspondendo à inscrição como imóvel sem matrícula, Imóvel Especial de Preservação (IEP), imóvel Tombado pela FUNDARPE e Imóvel Tombado pelo IPHAN, respectivamente. Através da planta das ZEPH's, foi feita a identificação visual dos imóveis cadastrados, conferida com as listas obtidas, e inseridos os valores correspondentes no campo referido.

O tema Aest_lotesrecebeu os dados da tabela de dados montada, através da comparação entre os campos DSQFL comuns à tabela montada e à tabela de dados do programa, sendo criados os campos correspondentes: Área total de Construção, número de Pavimentos, Forma do Terreno, Testada Principal, Testada Fictícia, 
Recuos, Condição de Ocupação, Tipologia da edificação, Estado de Conservação, Patrimônio e Valor Venal.

O tema Aest_lotesfoi completado com os campos: área lotes, com área calculada a partir do polígono de cada lote; área_ocupada, a partir da área encontrada no tema edificações; área_livre, da diferença calculada entre os dois campos anteriores; área_lâmina, estimada a partir da divisão da área total de construção pelo número de pavimentos, coef_util, calculado da divisão da área total de construção pela área encontrada do lote, $T S N$, correspondendo à estimativa da taxa de solo natural, calculada a partir do percentual de área livre em relação ao terreno.

\section{Desenvolvimento do SIG}

\section{Imóveis para a ocupação por substituição}

Procura-se por Lotes que permitam uma ampliação da área construída através da substituição de imóveis subutilizados para se chegar à área de construção máxima permitida para a zona. Tenta-se identificar lotes vazios ou subaproveitados, edificações abandonadas ou em ruinas procurando otimizar o uso do solo urbano. São discutidas as áreas mínimas em função do empreendimento buscado, podendose chegar a mais de uma solução de faixa de renda, mas não se propõe um uso especifico uma vez que a intenção é a de se oferecer estes lotes à iniciativa privada. $\mathrm{Na}$ análise realizada se toma como exemplo o uso comercial para estabelecer parâmetros que auxiliem na escolha dos lotes.

\section{Estudo da área mínima do lote}

A escolha de um terreno para a locação de um empreendimento imobiliário passa principalmente pela análise de sua área: é esta que define a área máxima de construção permitida, através do Coeficiente de utilização/Aproveitamento estabelecido na Lei de Uso do Solo (LUOS) de uma cidade. Outro fator fundamental é a sua largura, uma vez que será necessária uma largura mínima para poder respeitar os afastamentos legais e manter uma lâmina mínima aproveitável, $\mathrm{p}$. ex. o código municipal do Recife prevê um acréscimo de $25 \mathrm{~cm}$ nos afastamentos a cada pavimento acrescido, na altura do edifício, a partir do $4^{\circ}$ pavimento.

Para a definição da largura mínima do lote, foi estabelecida a posição da escada transversal ao terreno onde é acrescentada a largura da circulação, as espessuras de paredes resultando em uma largura de lâmina de $6,40 \mathrm{~m}$, acrescentando-se o afastamento de $3,00 \mathrm{~m}$ para cada lado (conforme a legislação municipal para a zona) se chega a uma largura mínima de lote de 12,50 m, ilustrado pela Figura 2. 


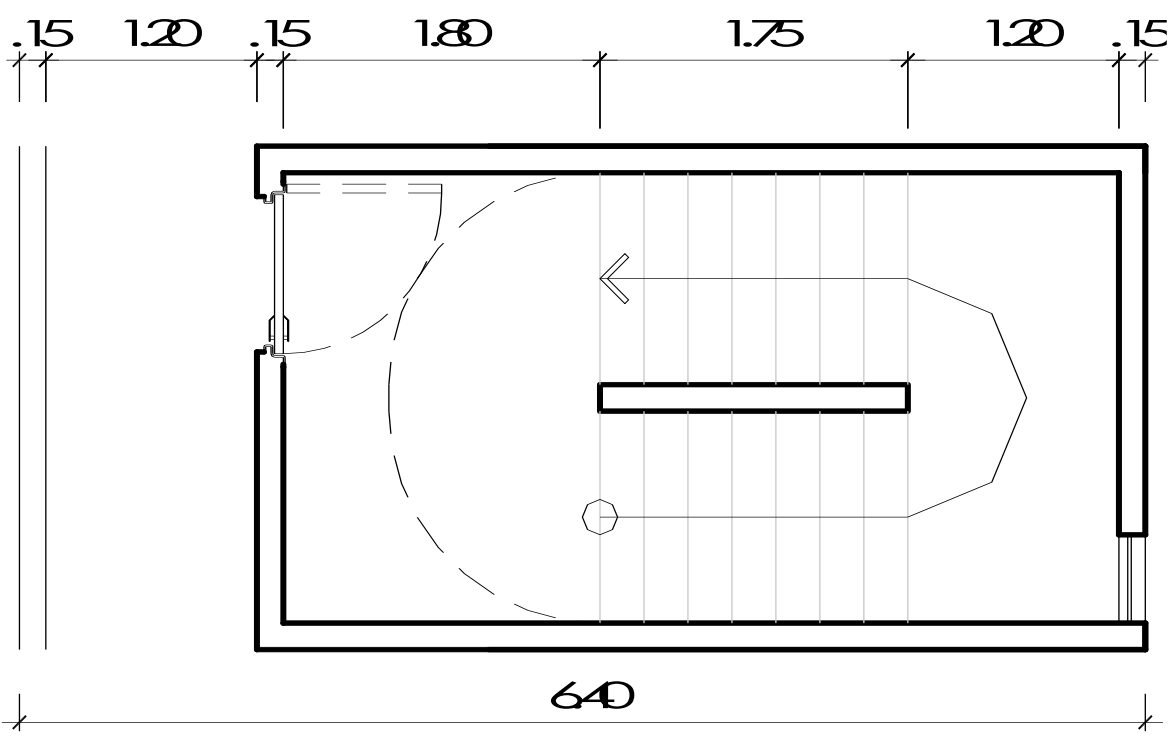

Figura 2. Definição da largura da lâmina em função da escada.

Considerando-se os afastamentos frontal inicial de $5,00 \mathrm{~m}$ e o de fundos inicial de 3,00 m, veremos que um terreno de $25,00 \mathrm{~m}$ de profundidade terá uma lâmina de $17,00 \mathrm{~m}$ de comprimento, resultando em uma área de lâmina de $110,50 \mathrm{~m}^{2}$. Considerando-se a área do terreno, 12,50 m x 25,00 m=312,50 $\mathrm{m}^{2}$, e o coeficiente de utilização para a ZUP $1(4,0)$, teríamos uma área de construção permitida de $1.250,00 \mathrm{~m}^{2}$, o que nos permitiria construir 11,3 pavimentos. Porém, ao se aplicar a fórmula dos afastamentos finais para a zona estudada (Eq. 01 extraída da LUOS (Recife, 1997a)), vemos que:

Para:

$$
\text { Af }=\mathrm{Ai}+(\mathrm{n}-4) 0,25
$$

Temos:

$$
\mathrm{Af}_{\text {frontal }}=5,00+(11-4) 0,25 \quad \Rightarrow \mathrm{Af}_{\text {frontal }}=6,75 \mathrm{~m}
$$

Também:

$$
\mathrm{Af}_{\text {lateral e fundos }}=3,00+(11-4) 0,25=>\mathrm{Af}_{\text {lateral e fundos }}=4,75 \mathrm{~m} \text {. }
$$

Utilizando os afastamentos finais calculados para 11 pavimentos, temos que a lâmina teria:

$$
\begin{array}{ll}
\text { Largura: } & 12,50 \mathrm{~m}-4,75 \mathrm{~m}-4,75 \mathrm{~m}=3,00 \mathrm{~m} \\
\text { Comprimento: } & 25,00 \mathrm{~m}-6,75 \mathrm{~m}-4,75 \mathrm{~m}=13,50 \mathrm{~m}
\end{array}
$$


$\mathrm{O}$ que resulta em uma lâmina antieconômica, pela sua pouca largura. Se reduzimos a altura para 6 pavimentos, teremos (com o uso da Equação 1):

$\mathrm{Af}_{\text {frontal }}=5,00+(6-4) 0,25 \quad \Rightarrow \mathrm{Af}_{\text {frontal }}=5,50 \mathrm{~m}$

$\mathrm{Af}_{\text {lateral e fundos }}=3,00+(6-4) 0,25 \Rightarrow \mathrm{Af}_{\text {lateral e fundos }}=3,50 \mathrm{~m}$

Resultando numa lâmina de:

Largura: $\quad 12,50 \mathrm{~m}-3,50 \mathrm{~m}-3,50 \mathrm{~m}=5,00 \mathrm{~m}$

Comprimento: $\quad 25,00 \mathrm{~m}-5,50 \mathrm{~m}-3,50 \mathrm{~m}=16,00 \mathrm{~m}$

Uma lâmina de 5,00 m nos permite o uso de uma área com largura de 3,35m (são subtraídas a circulação e espessuras de paredes), o que é perfeitamente viável para salas comerciais, escritórios, consultórios médicos e outros mais, porém a área construída será, aproximadamente, de $480,00 \mathrm{~m}^{2}$, ou coeficiente de utilização $=1,3$ (Figura 3).

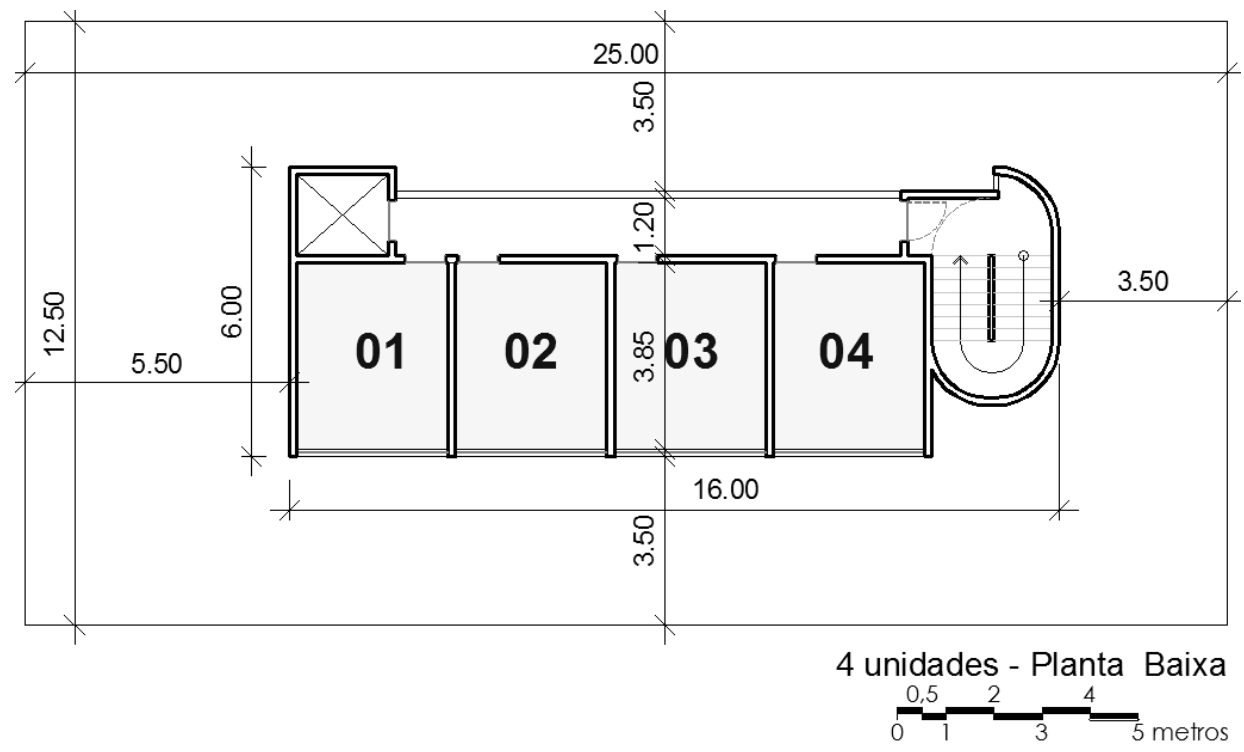

Figura 3. Exemplo de planta para prédio comercial (largura da lâmina).

Como pode ser visto, o aproveitamento total do coeficiente de utilização nem sempre é possível, dependendo do projeto arquitetônico a ser implantado pode-se maximizar o seu uso, mas pode-se verificar que um lote padrão mínimo teria $12,50 \mathrm{~m} \times 25,00 \mathrm{~m}$, com uma área de $312,50 \mathrm{~m}^{2}$. 


\section{Parâmetros analisados para a escolha dos lotes}

Área dos Lotes

Conforme visto anteriormente, serão selecionados os lotes com área mínima de $300,00 \mathrm{~m}^{2}$.

\section{Largura dos lotes}

Como também foi visto anteriormente, os lotes terão que ter largura mínima de $12,50 \mathrm{~m}^{2}$. A tabela do CADIM possui o dimensionamento da frente do lote, denominada Testada Principal, a qual representa a largura do lote na divisa da rua. Deve-se pensar na existência de lotes que tenham a sua largura, na divisa com a rua, mais estreita que a dimensão procurada porem que tenham maiores larguras no meio e fundos. Para tanto será analisado, também, o próximo item para estes casos.

\section{Formato do lote e Testada Fictícia}

No caso do lote ter uma largura abaixo daquela procurada, será verificado o formato do mesmo e, sendo este classificado como "IRREGULAR", será analisada a "TESTADA FICTICIA". Esta é mostrada no CADIM e é um reajuste da metragem medida quando ela é muito estreita, mas o lote possui grandes áreas de terreno no seu interior e vice-versa. O Código Tributário Municipal (CTM) da Cidade do Recife (Recife, 1991), no seu Art. 24, §1º, estipula o seu cálculo como sendo (Equação 2):

$\mathrm{TF}=(2 \times \mathrm{S} \times \mathrm{T}) /(\mathrm{S}+(\mathrm{T} . \mathrm{P}))$

Sendo:

$\mathrm{S}=$ area do Terreno

$\mathrm{T}=$ Testada Principal

$\mathrm{P}=$ Profundidade Padrão*

* Em Recife é considerada como sendo 30,00 m, de acordo com o CTM.

A Testada Fictícia será considerada por ser um indicativo de que o lote poderá ser escolhido. Com o fim de determinar um valor de referência para a Testada Fictícia, a partir do qual o lote será escolhido, adotou-se o seguinte raciocínio:

i. Foram escolhidos aleatoriamente 3 lotes com Testada Principal de 12,50 m e verificou-se o valor para a Testada Fictícia aplicando a fórmula do CTM (2):

Lote A: área do lote de $621,87 \mathrm{~m}^{2}$

$\mathrm{TF}=(2 \times 621,87 \times 12,50) /(621,87+(12,50 \times 30,00) \Rightarrow \mathrm{TF}=15,60 \mathrm{~m}$ 
Este mesmo lote teria, caso fosse de formato 'REGULAR', dimensão de $12,50 \mathrm{~m}$ $\mathrm{x} 49,75 \mathrm{~m}$.

Lote B: área do lote de $194,00 \mathrm{~m}^{2}$

$\mathrm{TF}=(2 \times 194,00 \times 12,50) /(194,00+(12,50 \times 30,00)=>\mathrm{TF}=8,52 \mathrm{~m}$

Caso fosse de formato 'REGULAR', a dimensão seria de 12,50 m x 15,52 m

Lote C: área do lote de $375,00 \mathrm{~m}^{2}$

$\mathrm{TF}=(2 \times 375,00 \times 12,50) /(375,00+(12,50 \times 30,00) \Rightarrow \mathrm{TF}=12,50 \mathrm{~m}$

As dimensões caso fosse 'REGULAR', seriam de $12,50 \mathrm{~m} \times 30,00 \mathrm{~m}$

Assim, pode-se verificar que a Testada Fictícia, para uma mesma Testada Principal, aumenta com o aumento do comprimento ou da área do lote.

ii. Calculou-se a Testada Fictícia para a Testada Principal (largura) e área de lote desejadas:

$$
\mathrm{TF}=(2 \times 300,00 \times 12,50) /(300,00+(12,50 \times 30,00))=>\mathrm{TF}=11,11 \mathrm{~m}
$$

Dessa forma, adotou-se a Testada Fictícia com 11,20 m, ou maior, como sendo a medida de referência.

Estado de conservação da edificação contida no lote

Neste item houve a procura por imóveis classificados como "RUINA" para proceder na ocupação por substituição da edificação existente, sendo assim os lotes selecionados neste quesito serão encaminhados ao item 'Polígonos de Preservação'e os que não, para o item a seguir.

\section{Condição de ocupação}

Neste item os imóveis que foram classificados como "FECHADO", "VAZIO", "PARCIALMENTE OCUPADO" ou "NÃO EDIFICADO" serão selecionados e encaminhados ao próximo item.

\section{Polígonos de Preservação}

Se o lote estiver contido por algum Polígono de Preservação, do IPHAN ou Setor de Preservação Ambiental (SPA) ou Setor de Preservação Rigoroso (SPR) municipais será descartado, senão é encaminhado ao próximo item.

\section{IEPs e Imóveis Tombados}

Caso o Lote selecionado contenha um Imóvel Especial de Preservação (IEP) ou um Imóvel Tombado será encaminhado ao item seguinte, caso contrário será escolhido. 


\section{Afastamentos laterais}

Os Lotes encaminhados no item anterior serão checados com a intenção de averiguar se possuem recuos classificados como "FRONTAL/LATERAL" e/ou "LATERAL" sendo descartados os que não atenderem este item.

\section{Verificação dos recuos laterais}

Analisando as plantas coletadas procura-se dimensionar os afastamentos laterais encontrados no item anterior, com o fim de verificar se possuem afastamentos em uma das laterais, com $3,00 \mathrm{~m}$ ou mais, que permitam a circulação para seu interior sendo selecionados em caso positivo e descartados em caso negativo.

\section{Esquema de seleção de lotes para a Ocupação por Substituição}

A Figura 4 apresenta um esquema gráfico ilustrando a linha de raciocínio adotada para a análise realizada.

\section{Analise espacial}

Inicialmente foram selecionados 612 eventos atendendo à condição de área de lote $>300,00 \mathrm{~m}^{2}$ e TP $>=12,50 \mathrm{~m}$ e acrescentados 162 eventos de lotes que atendem à condição de área mínima mas não atendiam à condição de TP mas classificados de forma "IRREGULAR" e atendendo o critério de TF $>=11,20 \mathrm{~m}$.

Foram selecionados os lotes que continham edificações em estado de conservação classificado como "RUINA" e descartados os lotes com a condição de ocupação diferente de "OCUPADO", restando 278 lotes na seleção inicial.

A seguir foram descartados os lotes contidos pelos polígonos de preservação do IPHAN, SPR e SPA existentes na área de estudo, devido à limitação de gabarito, ficando a seleção com 217 lotes.

Como na seleção obtida não houve a incidência de IEPs e imóveis tombados pela FUNDARPE, a seleção continuou a mesma, ficando o total de 88 lotes selecionados.

\section{Resultados obtidos}

Durante a realização da análise verificou-se 1 evento no qual a área total de construção era muito superior à área do lote (coeficiente de utilização acima de 1) e que era mostrado no cadastro municipal como um imóvel de 23 pavimentos, enquanto que na Planta da Unibase apresentava um lote contendo uma pequena edificação, sendo portanto excluído da seleção.

Outra situação verificada foi a de uma inscrição de lote no Cadastro Municipal que foi descartada quando na Planta Unibase verificou-se tratar de um canteiro central de avenida. 


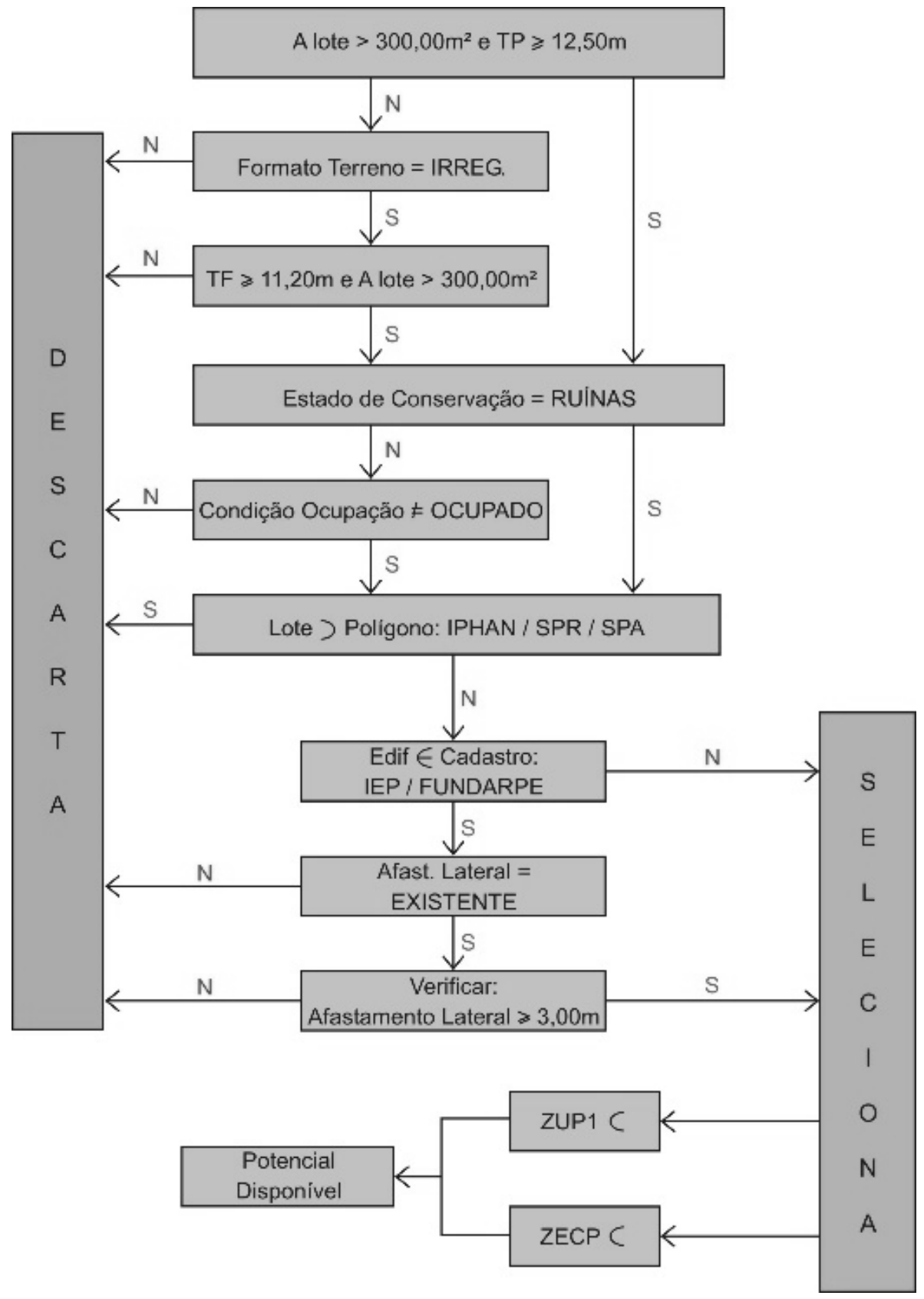

Figura 4. Esquema gráfico da seleção "SUBSTITUIÇÃO”. S - Sim e N - Não. 
No total foram selecionados 86 lotes com a área mínima exigida que foram examinados em relação à sua TP sendo menor que a largura mínima estabelecida. Nesse grupo, 26 lotes foram identificados com TP menor mas atendiam o critério estipulado para a TF cuja TP variavam de $9,25 \mathrm{~m}$ a $12,00 \mathrm{~m}$.

A análise procurou verificar se a o lote classificado como de forma "IRREGULAR" aumentava de largura permitindo acomodar a lâmina mínima proposta e foi encontrado que:

- 1 lote com $\mathrm{TP}=9,25 \mathrm{~m}$ foi descartado pois sua largura diminuía para dentro;

- 2 lotes com $\mathrm{TP}=10,00 \mathrm{~m}$ que não aumentavam de largura, sendo descartado um e mantido o outro por se encontrar junto a outro lote da amostra selecionada, o que poderia permitir uma operação de remembramento de lotes com a finalidade de implantar um grande empreendimento;

- 4 lotes com $\mathrm{TP}=11,00 \mathrm{~m}$, sendo descartados 02 e mantidos os outros 02 que eram vizinhos e que também se encontram juntos à um terceiro que fazia parte da seleção;

- 19 lotes com $\mathrm{TP}=12,00 \mathrm{~m}$ nos quais 08 foram descartados e forma mantidos 09 que se encontravam lado a lado e 02 que eram vizinhos a outros lotes pertencentes à seleção.

- A amostra resultante identificou 74 lotes somando $70.400 \mathrm{~m}^{2}$, mostrados na Figura 5, que se utilizados os parâmetros urbanísticos para a Zona de Urbanização Preferencial 1 (ZUP1) e da Zona de Especial de Comercio Principal (ZECP), conforme a pertinência do lote selecionado a uma ou a outra zona, permitiriam a construção por substituição e a criação de $280.000 \mathrm{~m}^{2}$.

- Analisando os dados tabulares dos lotes selecionados observa-se que a média do coeficiente de construção (área construída dividida pela área do lote) praticado é de 0,3 sendo o maior coeficiente encontrado de 1,8 (01 evento). Uma vez que o coeficiente permitido na ZUP1 é 4,0 e na ZECP é 7,0 pode-se entender melhor a escolha de ocupação por 'substituição' das edificações existentes.

\section{Imóveis para a Transferência do Potencial Construtivo}

A Transferência do Direito de Construir (TDC) é um instrumento de indução do desenvolvimento urbano previsto no Estatuto da Cidade (Brasil, 2005) que permite exercer em outro local, ou alienar, o direito de construir previsto no plano diretor ou em legislação urbanística. É uma ferramenta que pode ser usada para preservar imóveis de interesse histórico, ambiental, paisagístico, social ou cultural.

A TDC é uma forma de recuperação do valor econômico que o lote perde ao serem estipuladas restrições à construção (p.ex. a fixação de gabaritos de altura para a preservação do entorno urbano) ou é estabelecido a obrigatoriedade de preservação da edificação existente, impossibilitando a sua demolição e o aproveitamento máximo permitido pelo coeficiente de utilização. 


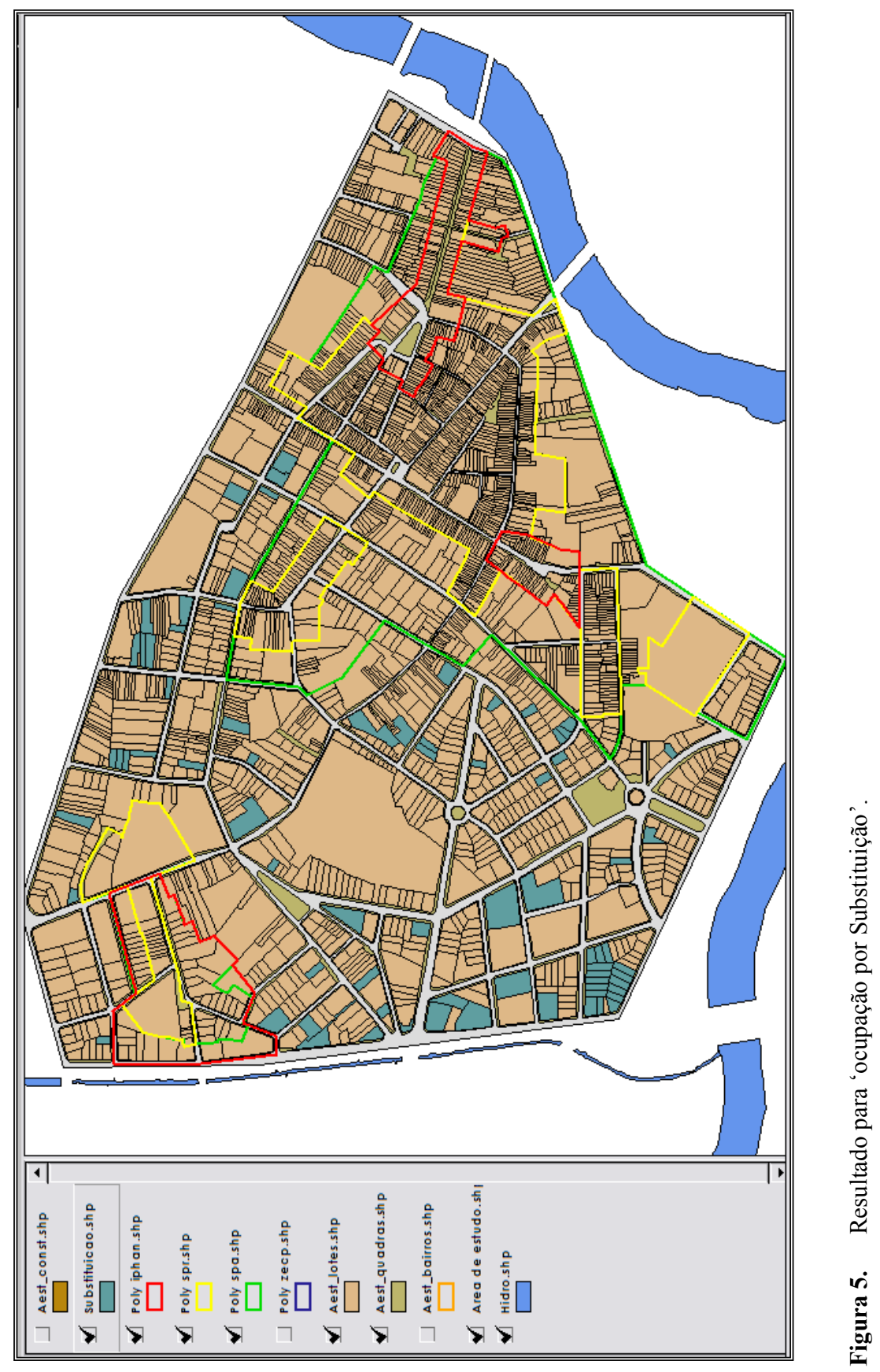


No Recife a Lei 16.284-97 (Recife, 1997b) define os Imóveis Especiais de Preservação (IEP) e estabelece as condições de preservação e assegura compensações e estímulos.

Quando o IEP não possuir área remanescente no seu terreno poderá transferir todo o potencial construtivo inerente ao imóvel preservado para outra área (Recife, 1997b, Art. $21, \S 2^{\circ}$ ).

\section{Área de estudo}

$\mathrm{Na}$ área de estudo delimitada, são encontrados 2.235 lotes dos quais 257 lotes se encontram inseridos no Polígono de Preservação do IPHAN, 1.011 lotes no polígono do SPR e 314 no polígono do SPA. No cadastro de IEPs constam 10 imóveis situados na área de estudo e 8 imóveis tombados pela FUNDARPE além de 4 imóveis declarados monumentos pelo IPHAN.

\section{Produto procurado}

Procura-se avaliar a disponibilidade de potencial construtivo não edificado nos lotes contidos pelos polígonos de preservação do IPHAN, dos SPR e SPA, bem como dos IEPs e imóveis tombados pela FUNDARPE e IPHAN com a finalidade de quantificar o total de área de construção que poderia ser transferido para outros lotes da área de estudo.

\section{Parâmetros usados para a seleção}

Polígonos de preservação

Os lotes que se encontrarem contidos por algum dos polígonos de preservação do entorno mencionados serão selecionados e encaminhados ao item 'Classificação em função da Zona Urbana'.

\section{IEPs e imóveis tombados}

Os lotes que contiverem edificações preservadas ou tombadas sem estar inseridos em algum dos polígonos de preservação, serão selecionados e encaminhados ao item seguinte.

\section{Classificação em função da Zona Urbana}

Os lotes anteriormente selecionados serão classificados em função da sua localização numa ZUP1 ou ZECP, isso porque as zonas possuírem diferentes parâmetros urbanísticos. A ZUP1 possui coeficiente de aproveitamento 4,0 e Taxa de Solo Natural de $25 \%$ enquanto que a ZECP possui um coeficiente de aproveitamento de 7,0 e TSN de $20 \%$. 


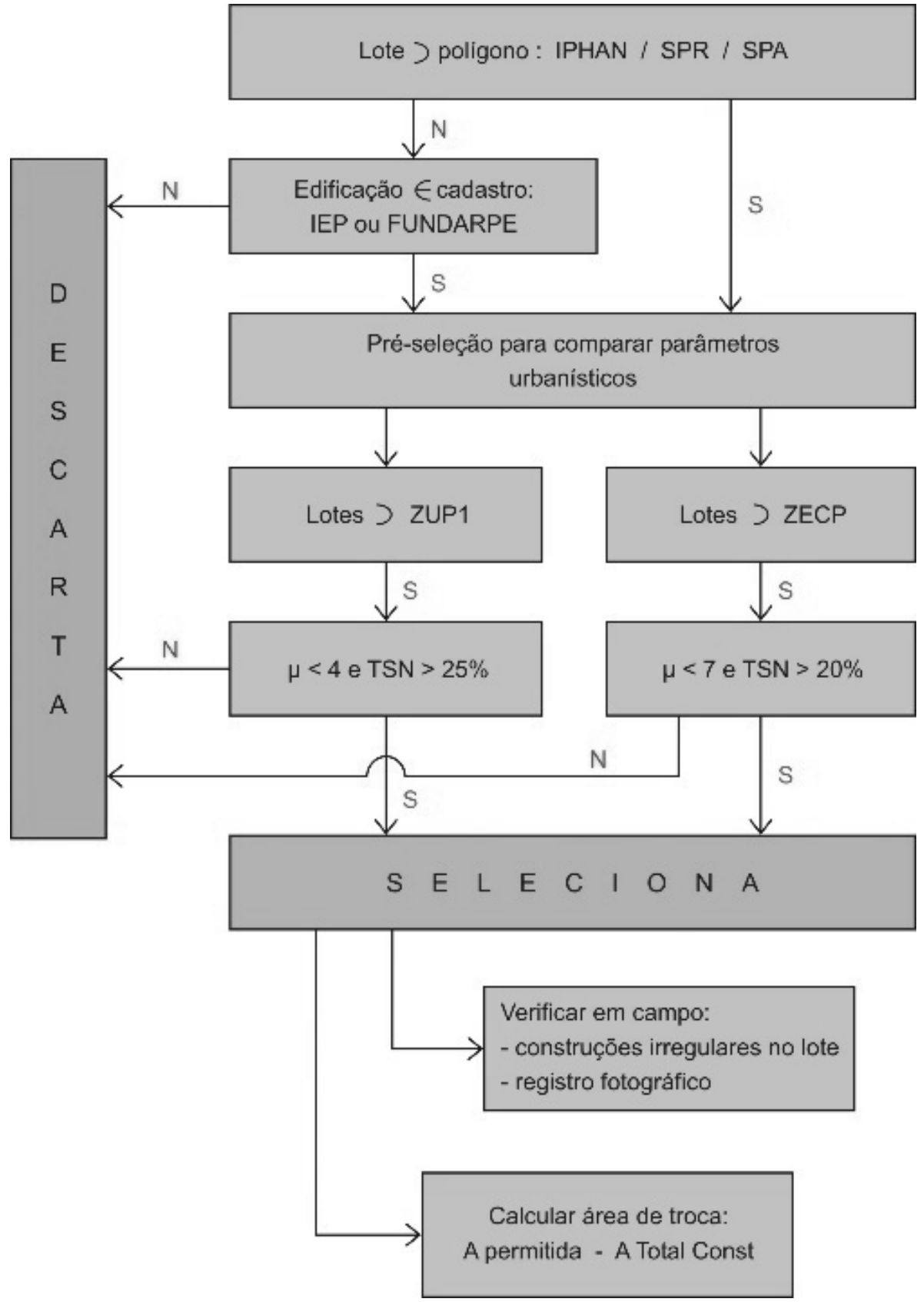

Figura 6. Esquema gráfico da seleção "TDC". 


\section{Analise da área construída}

A fim de encontrar o potencial construtivo remanescente em cada lote, é extraída a área total de construção do CADIMO e dividida pela área do lote obtendo-se o coeficiente de aproveitamento praticado, este será comparado com o coeficiente de utilização permitido para a Zona sendo selecionados os lotes que não atingem o valor máximo e descartados os que atingem ou superam este valor.

\section{Analise da TSN}

A TSN será analisada para determinar a viabilidade de construção no próprio lote, no caso de uma TDC parcial, onde parte da área de construção permitida é cedida a outro lote e parte é utilizada no próprio lote. Isto é considerado porque esta transferência limita-se, a 1,0 unidade no coeficiente de utilização permitido do imóvel receptor (Recife, 1997a Art. 103, inciso I da LUOS e Recife, 1997b Art. 29, $\S 1^{\circ}$ da Lei de IEPs). Outrossim, a Lei de IEPs permite a transferência fracionada, ou seja, para mais de um imóvel.

\section{Esquema de seleção de lotes para a TDC}

O diagrama, ilustrado na Figura 6, apresenta a linha de raciocínio adotado para a análise pretendida e a partir da qual serão realizadas as consultas no SIG a fim de encontrar os lotes que respondam ao produto pretendido.

\section{Seleção dos lotes através da análise espacial}

Inicia-se selecionando os lotes contidos ou cortados pelos polígonos de preservação do IPHAN, SPR ou SPA totalizando 1.336 lotes selecionados.

A seguir são acrescentados os lotes com IEPs ou com edificações tombadas pela FUNDARPE, somando 07 lotes à seleção inicial.

Do total são descartados os lotes pertencentes à Zona Especial de Interesse Social (ZEIS), contida na SPA, por obedecerem a parâmetros específicos onde não incide a TDC, resultando numa seleção de 1.336 lotes.

\section{TDC na ZUP1}

Os 1.336 lotes selecionados foram separados conforme a Zona. Aqueles que não estavam contidos pela ZECP foram avaliados para saber se possuem coeficiente de utilização menor que 4,0 e TSN maior que $25 \%$, sendo selecionados 490 lotes que são classificados em função do coeficiente de utilização praticado, na Figura 7 (cor mais escura para lotes de menor coeficiente). 


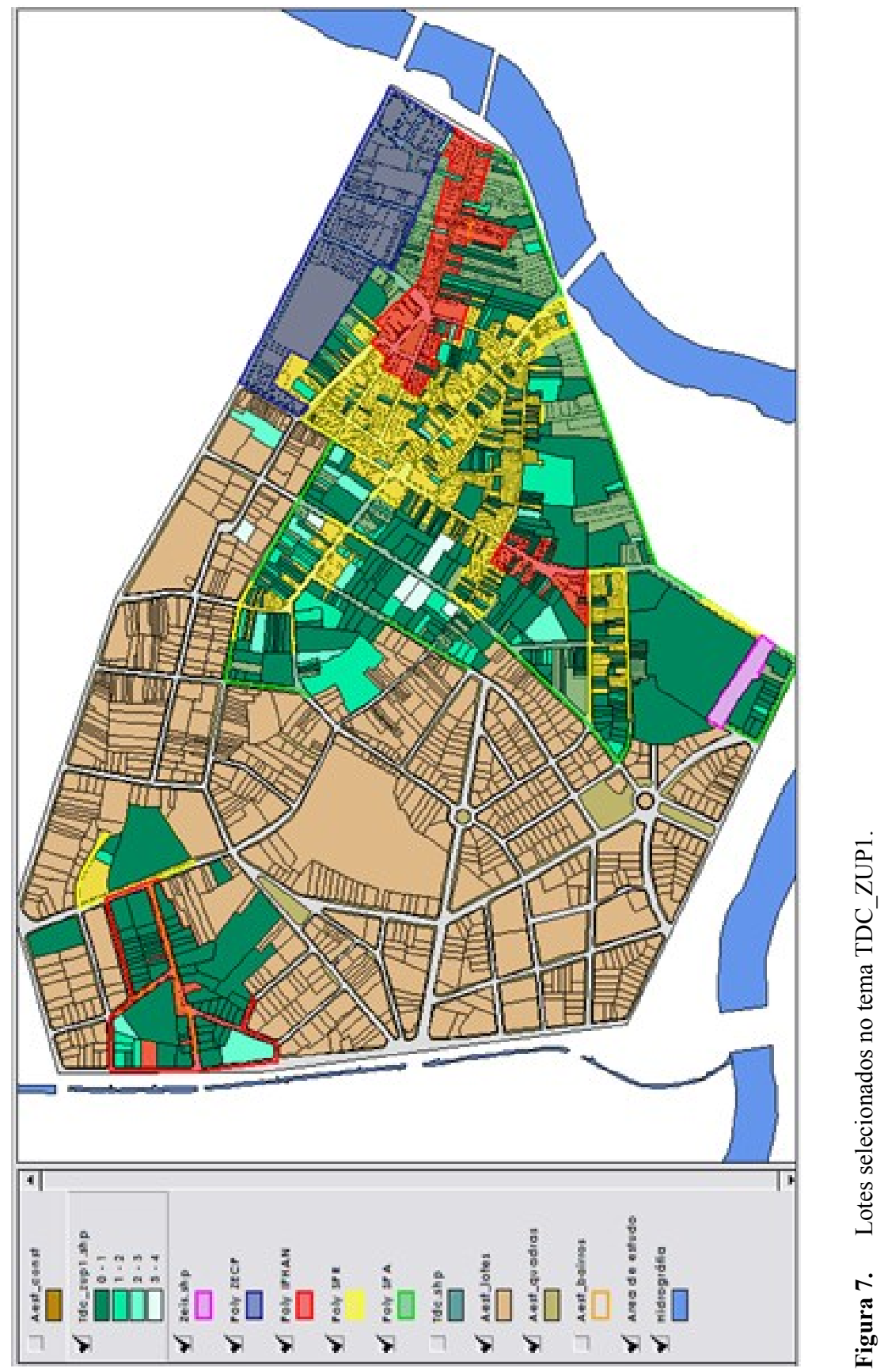




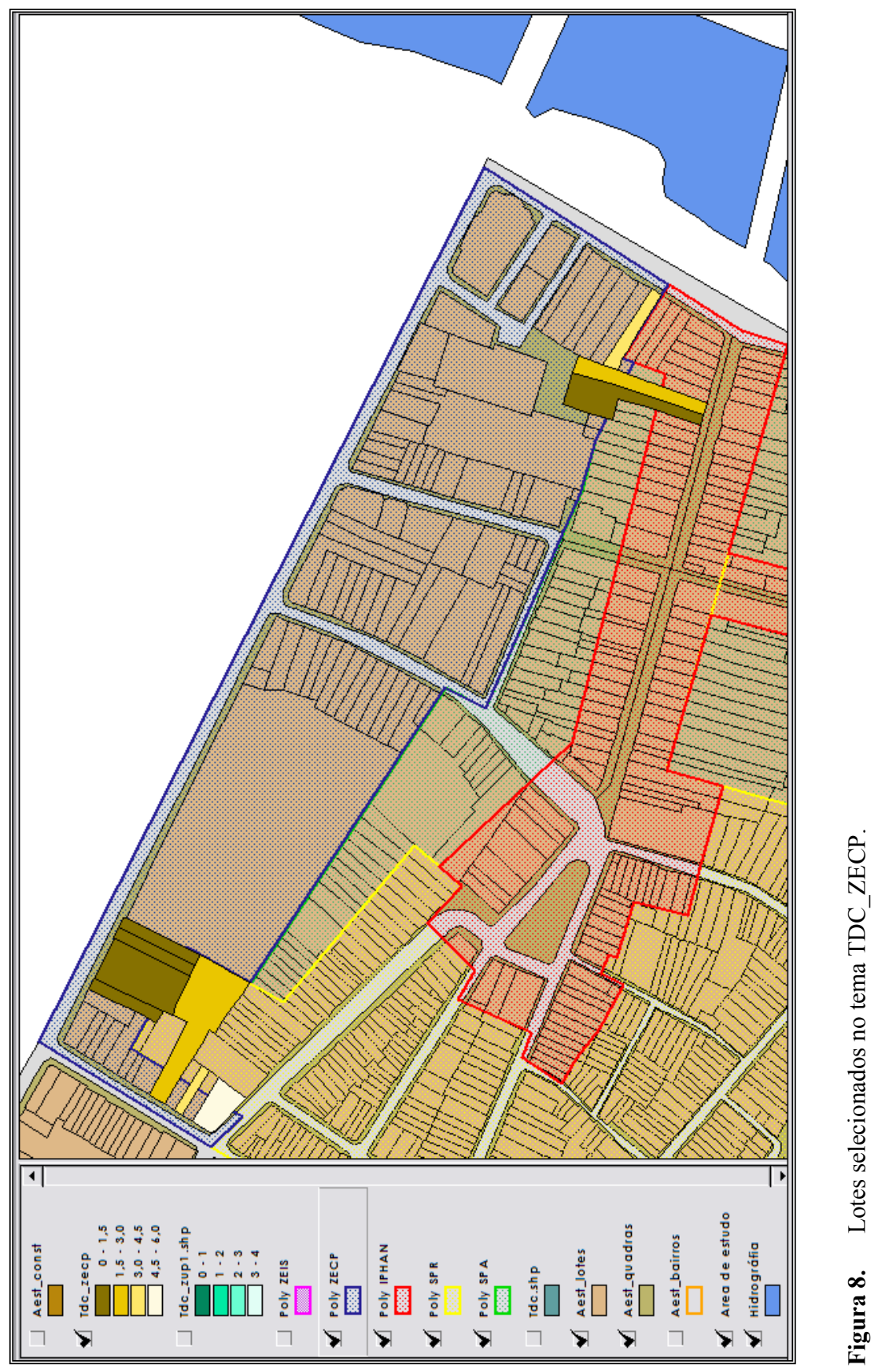




\section{TDC na ZECP}

Os selecionados no item 6.4 que se encontram contidos pelo polígono da ZECP, são avaliados com relação ao coeficiente de utilização praticado se é menor que 7,0 e se a TSN apresentada é maior que 20\%. Como resultado são selecionados 10 lotes que atendem as condições apresentadas e que são ilustrados pela figura 08 (cor mais escura para lotes de menor coeficiente).

\section{Resultados obtidos para a TDC}

$\mathrm{Na}$ análise realizada foi encontrada uma disponibilidade de $1.107 .314 \mathrm{~m}^{2}$ para a ZUP1 e de $37.776 \mathrm{~m}^{2}$ na ZECP, verificado nos dados tabulares.

O cálculo foi realizado considerando a área construída no lote original sendo reduzida do total possível de área de construção e que estava sendo transferida. Em obediência à Lei de IEPs (Recife, 1997b).

Em lotes com IEP, não foi contabilizado a área de construção do IEP, seguindo a mesma lei. Pode-se, em casos que só exista o IEP no lote, transferir integralmente a área obtida pelo coeficiente de utilização para outro(s) imóvel(eis). Foram encontrados 7 casos nesta situação.

Os imóveis de preservação que pertencem ao setor público (federal, estadual ou municipal) não foram contabilizados, pois a TDC equivale à venda de patrimônio e, sendo este imóvel de interesse histórico ou cultural pertencente ao Erário Público, esta negociação segue uma regulamentação específica.

Também os imóveis de preservação de propriedade do clero (1 casos encontrado), não foram contabilizados, uma vez que estes imóveis recebem auxílio, através de verbas públicas, para a sua conservação.

\section{Conclusões e recomendações}

Os processos de identificação das áreas passíveis de requalificação, de avaliação das intervenções propostas, assim como as análises prévias e diagnósticos para os projetos necessitam de informações territoriais detalhadas e precisas que podem e devem ser disponibilizadas por um Cadastro Territorial Multifinalitário atualizado e confiável.

O uso de um Sistema de Informações Geográficas permite e agiliza a análise dos dados coletados e referenciados espacialmente, possibilita a realização de inúmeros processos de seleção atendendo a qualquer parametrização, desde que esteja fundamentada nos dados de entrada. Porém, a confiabilidade dos resultados obtidos está proporcionalmente relacionada à consistência dos dados inseridos.

A disponibilidade de uma base cartográfica atualizada é a principal fonte de dados gráficos para um sistema cadastral atualizado. É, portanto, de fundamental 
importância observar os métodos e técnicas utilizadas, no projeto cartográfico, para a inserção de novos dados durante as atualizações.

A implementação de um Cadastro Territorial Multifinalitário, exige um esforço integrado de todos os futuros usuários, porém a sua atualização se torna muito mais simples, uma vez que cada usuário participa contribuindo com as ferramentas de que já dispõe.

Ainda que tenham sido encontradas algumas inconsistências nos dados adotados, em decorrência da defasagem entre as várias fontes pesquisadas e da desatualização por parte dos dados cartográficos (demonstrando uma vez mais a importância de um cadastro atualizado), os resultados encontrados se mostraram promissores.

\section{Bibliografia}

Águila, M.; Erba, D. (2006). "El rol del Catastro en el registro del território", Notas do curso: Aplicaciones del Catastro Multifinalitario en la definición de políticas de suelo urbano, Massachussets, Lincoln Institute for Land Policies-Educación a Distancia.

Álcazar-Molina, M., (2007). "Catastro, propiedad y prosperidad", Jaén, Publicaciones de la Universidad de Jaén.

Bonilla, R.J., (2007) "Requalificação urbana a partir de informações de cadastros territoriais e sistemas de informações geográficas", Recife: O Autor.

Brasil (2005). "Lei 10.257/2005 - Estatuto da Cidade", disponível em $<w w w$.planalto. gov.br/>, acessado em 10/09/2005.

Carneiro, Andrea F.T. (2003). "Cadastro Imobiliário e Registro de Imóveis”, A Lei 10.267/2001, Decreto 4.449/2002, Atos Normativos do Incra, Coleção IRIB em debate, Porto Alegre, Sérgio Antônio Fabris, 272 pp.

Dang, H.V. (2007). "E-administration of land based on dialog between government and people", Decision Makers Meeting on Good Administration of Land in Asia and the Pacific: Land Administration for Poverty Reduction and Economic growth, Tokyo.

Erba, D.A. (2005). Cadastro Multifinalitário como instrumento da política fiscal e urbana, Rio de Janeiro, Ministério das Cidades.

Graafland, A. (1999). Municipal geo-information infrastructure: how to find a way and oases in a long journey through the desert, UDMS.

Hawerk, W., (2006). "Cadastre for the 21st century: the German way", XXIII International FIG Congress, Shaping the change.

Piumeto, M. (2006). "Usos y aplicaciones de los Sistemas de Información Geográfica", Notas do Curso: Aplicaciones del Catastro Multifinalitario en la 
Definición de Políticas de Suelo Urbano, Massachussets, Lincoln Institute for Land Policies-Educación a Distancia.

Recife (1991). Prefeitura Municipal. Secretaria de Finanças. "Lei 15.563/91 Código Tributário Municipal”. Recife: Diário Oficial do Município, disponível em $<$ http://www.recife.pe.gov.br/pr/secfinancas/legislacao/codtrib.php $>$.

Recife (2005). "Diagnóstico Urbano". Seções I a IV, disponível em: $<$ http://www.recife.pe.gov.br/pr/secplanejamento/planodiretor $>$, acessado em $10 / 09 / 2005$.

Recife, Secretaria de Planejamento, Urbanismo e Meio Ambiente (2005a). Atlas Municipal de Desenvolvimento Humano no Recife, SEMPLAM, CD rom, ESM Consultoria.

Recife, (1997a). "Lei No 16.176/96 - Lei de Uso e Ocupação do Solo da Cidade do Recife". Recife: Diário Oficial do Município, disponível em $<$ http://www.recife.pe.gov.br>.

Recife, (1997b). "Lei N ${ }^{\circ}$ 16.284/97 - Imóveis Especiais de Preservação - IEP". Recife: Diário Oficial do Município, disponível em <http://www.recife. pe.gov.br>.

Riecken, Jens, (2007). "Spatial information management in the context of SDI and e-government: the German approach", XXX FIG Working Week and General Assembly: Strategic Integration of Surveying Services, China.

SarubbiNeto, Prosperino (2005). "Atualização de cadastro fiscal com suporte em imagens de satélite de alta resolução", Monografia (Especialização em Tecnologias da Geoinformação), Departamento de Cartografia, UFPE. 